\title{
Analysis of recoverable waste heat of circulating cooling water in hot-stamping power system
}

\author{
Panpan Qin · Hui Chen · Lili Chen • \\ Chong Wang $\cdot$ Xiaoxiao Liu $\cdot$ Xiaojie Hu \\ Luning Yu $\cdot$ Shikui Liu
}

Received: 7 April 2012/ Accepted: 21 November 2012/Published online: 10 January 2013

(C) The Author(s) 2013. This article is published with open access at Springerlink.com

\begin{abstract}
This article studies the possibility of using heat pump instead of cooling tower to decrease temperature and recover waste heat of circulating cooling water of power system. Making use of heat transfer theory the article carried on analysis and calculation about recoverable waste heat of circulating cooling water in hot-stamping power system which includes hot-stamping, closing-in and extrusion intermediate frequency induction furnace. The results show that the whole process can recover a calorie which is $2.642 \times 10^{6} \mathrm{~kJ}$ per hour. Using the recycled calories can make 15.82 tons hot water per hour which is $60{ }^{\circ} \mathrm{C}$. So it can reduce burning capacity of coal $180.29 \mathrm{~kg} / \mathrm{h}$. The hot water can provide the needed water for production and workers bathing. This research shows that using heat pump to recover the waste heat of circulating cooling water is effectual. Realizing the use of waste heat, it can reduce pollution of condensing heat, reduce operating cost and noise of cooling tower, reduce site and the occupation of equipment, improve the production efficiency, and can also save the natural resources (fossil fuel-coal) and reduce the cost of needed hot water production.
\end{abstract}

Keywords Medium frequency heating .

Heat transfer theory - Circulating cooling water .

Recovery of waste heat

P. Qin · H. Chen $(\bowtie) \cdot$ L. Chen $\cdot$ C. Wang $\cdot$ X. Liu $\cdot$ X. Hu

School of Traffic and Mechanical Engineering,

Shenyang Jianzhu University, Shenyang 110168, China

e-mail: chenhui@sjzu.edu.cn

L. Yu $\cdot$ S. Liu

Liao Shen Industries Group Co. Ltd Technology Reform

Department, Shenyang 110045, China

\section{Preface}

With rapid growth of the economy, the contradiction between supply and demand of energy is becoming more and more prominent, government of all countries in the world attaches great importance to energy saving and emission reduction. The target of realizing energy saving and emission reduction, improving energy efficiency mainly depends on the industry field. China is in the middle or later stage of industrialization, industry is the main energy consumption field and also main emission source of pollutant. Energy consumption of industrial field in China accounts for about $70 \%$ of the total national energy consumption. Unit energy consumption of main industrial product in China is $30 \%$ higher than the international advanced level. Chinese energy utilization rate is only about $33 \%$ and it is $10 \%$ lower than developed countries. There is at least $50 \%$ of industrial energy which is discarded in a variety of forms in China. Therefore from another angle, Chinese industrial exhaust heat is abundant, widely exists in industrial production. Waste-heat resource accounts for about $17-67 \%$ of the total fuel consumption, recovery rate of waste heat reaches about $60 \%$, and waste heat of cooling medium which is a part of low-and-medium temperature waste-heat accounts for $20 \%$ of the total industrial waste heat resources (Lian et al. 2011; Li and Zhou 2007; Spoelstra et al. 2002; Zhou et al. 2002).

Liao Shen Industries Group CO.LTD needs a large number of recirculating cooling water to ensure hot-stamping production run smoothly. Formerly, they used cooling tower to cool water. In the process of cooling waste heat emitted into atmosphere directly, it not only creates squander but also causes thermal pollution. In response to energy conservation and emission reduction policy of chinese government, realizing the comprehensive utilization of 
energy, Liao Shen Industries Group decides to update the technology on condition that do not affect properties of original production, will use heat pump to cool recirculating cooling water of hot-stamping dynamic system.

This article did research and analyse about recoverable waste heat of circulating cooling water in hot-stamping power system of Liao Shen Industries Group. The results can make preparation for designment of waste-heat recovery system and selection of equipment.

\section{Analysis of production process}

The original production process

Put roughcast which weighs $32 \mathrm{~kg}$ into intermediate frequency induction furnace to heat to $1,200{ }^{\circ} \mathrm{C}$. Then three hydraulic presses separately complete techniques of cupping, punching and stretching, temperature of workpiece get down to $970{ }^{\circ} \mathrm{C}$. After punch forming, workpiece should be inspected whether its wall thickness and shape meet the requirements, otherwise workshop should stop the production to check and adjust facilities. After workpiece passes inspection, put it in the air to cool until below $200{ }^{\circ} \mathrm{C}$, remove its oxide skin to prepare for closing-in technology. Before the closing-in technology, workers put workpiece into intermediate frequency induction furnace to heat to $1,200{ }^{\circ} \mathrm{C}$. After closing-in technology, the temperature of workpiece is downed to $800{ }^{\circ} \mathrm{C}$, so workpiece needs to heat to $1,200{ }^{\circ} \mathrm{C}$ again in intermediate frequency induction furnace to prepare for warm extrusion technology. Through closing-in and warm extrusion technology workpiece attains the required shape and properties.

The improved production process

On the basis of original production process use three stations oil press to substitute for three hydraulic presses, make techniques of cupping, punching and stretching finished in a three stations oil press. So it not only reduces floor space, shortens working hours, but also cuts down energy consumption. Collation map of original production process and improved production process is shown as in Fig. 1. The part of double dots line is an improved production process that is different from the original production process. Their marked difference is different demand of temperature.

Through analysis of the new production process can know that the whole power system includes three stations oil press, intermediate frequency induction furnace of hotstamping, intermediate frequency induction furnace of closing-in and intermediate frequency induction furnace of warm extrusion.

\section{Analysis of power system}

The workpiece is heated by intermediate frequency induction furnace which can satisfy the different temperature requirement of technology. The temperature of circulating cooling water which is used to cool electric source and furnace body is rising constantly in heating process. In order to guarantee normal operation of the heating units, the circulating water should be cooled down timely. In the original production process cooling water is used to cool circulating water. This method is inevitably influenced by nature temperature, which cannot be controlled steadily and cannot achieve the aim of controlling temperature accurately and efficiently (Lu 2011; Hui 2011). In order to protect environment and save water, workshop intends to use heat pump to extract and use the heat of circulating cooling water.

The heated workpiece is stamped by oil press; through subsequent finish machining operations workpiece gets required shape and properties. Temperature of fuel tank is rising constantly in cyclic process. If oil temperature is exorbitant, it can reduce the viscosity of oil, makes oil leakage quicker, accelerates detrition of component part and oxidization of oil, and even affects normal work of the system (Wang et al. 2005; Li and Zhang 2010). So worker should pay more attention to maintain the normal operation of the cooling system, control temperature of pressure oil, stabilize pressure of oil, prolong service time of oil, increased efficiency of mechanical lubrication and decrease detrition.

\section{Analysis and calculation of recoverable waste heat in power system}

Needs and pressure of circulating water is shown in the Table 1.

In the production power of intermediate frequency induction furnace mainly used for heating workpiece, temperature rise of circulating water, self-heating of medium frequency power supply. Total heat of induction coil is from two parts, one produced when current passes through induction coil, the other is from heated roughcast whose heat crosses over furnace liner to induction coil.

\section{Hot-stamping}

(1) Circulating water of intermediate frequency induction coil mainly depends on the convection heat transfer happened when water flows in the tube to cool induction coil.

Mass flow of water is $80 \mathrm{t} / \mathrm{h}$ that is $22.22 \mathrm{~kg} / \mathrm{s}$. Induction coil has 25 turns, mass flow $\left(q_{\mathrm{m}}\right)$ of every turn is $0.889 \mathrm{~kg} / \mathrm{s}$. Induction coil is a square pipe which is $20 \mathrm{~mm} \times 25 \mathrm{~mm}$, 
Fig. 1 Collation map of original production process and improved production process

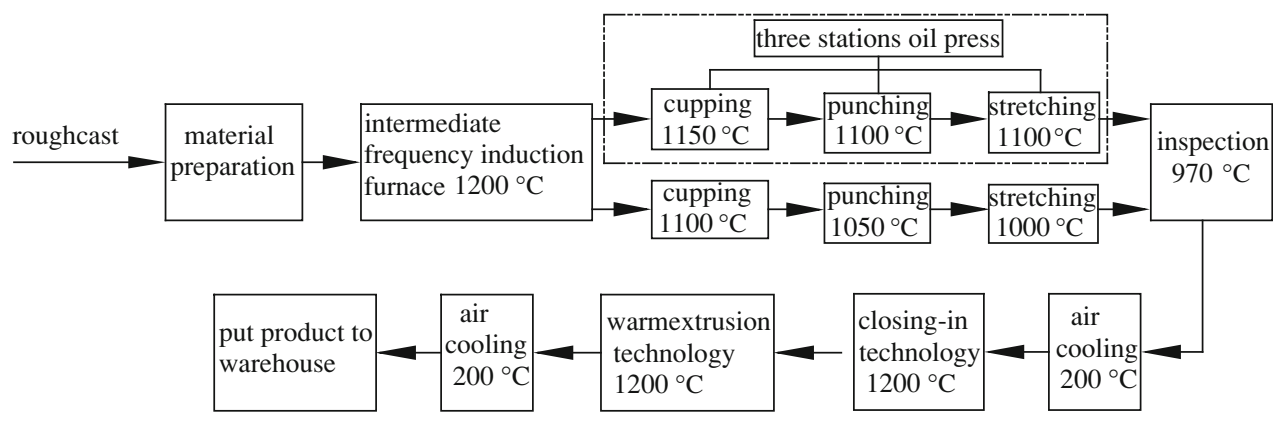

Table 1 Needs and pressure of circulating water in different technology

\begin{tabular}{lllll}
\hline $\begin{array}{l}\text { Productive } \\
\text { technology }\end{array}$ & $\begin{array}{l}\text { Rated power of } \\
\text { intermediate frequency } \\
\text { induction furnace }(\mathrm{kW})\end{array}$ & Equipment & $\begin{array}{l}\text { Water } \\
\text { yield } \\
(\mathrm{t} / \mathrm{h})\end{array}$ & $\begin{array}{l}\text { Water } \\
\text { pressure } \\
(\mathrm{Mpa})\end{array}$ \\
\hline Hot-stamping & 2,000 & Medium frequency power supply & 20 & 0.4 \\
& & Intermediate frequency induction coil & 80 & 100 \\
& \multirow{2}{*}{1,000} & Three stations oil press & 10 & 0.4 \\
Closing-in & \multirow{2}{*}{500} & Medium frequency power supply & 40 & 0.4 \\
& & Intermediate frequency induction coil & 0.4 \\
Warm extrusion & & Medium frequency power supply & 2.5 & 10 \\
& & Intermediate frequency induction coil & 0.4 \\
\hline
\end{tabular}

wall thickness of coil is $2.5 \mathrm{~mm}$. Coil is helical, diameter (D) is $180 \mathrm{~mm}$. Inlet temperature $\left(t_{1}\right)$ of water in coil is $20{ }^{\circ} \mathrm{C}$, pipe surface temperature $\left(t_{\mathrm{w}}\right)$ of coil is kept at $60{ }^{\circ} \mathrm{C}$. The calculation about outlet temperature $\left(t_{2}\right)$ of water and heat release $(\Phi)$ of coil is shown as follows (Chen et al. 2002; Chen et al. 2011, b; Wang 2001; Verzicco 2004; Ma 2008; Jeong 2009; Dogruoz 2010; Aziz 2012; Lei and Bengt 2006). Size of coil is shown as the Fig. 2 which designed in the light of actual production needs. Figure 2 shows 3 turns of induction coil.

Physical parameter of water at $25{ }^{\circ} \mathrm{C}$ is shown as follows.

$$
\begin{gathered}
\lambda=0.609 \mathrm{~W} /(\mathrm{m} \cdot \mathrm{K}) \quad c_{p}=4179 \mathrm{~J} /(\mathrm{kg} \cdot \mathrm{K}) \\
\eta=902.75 \times 10^{-6} \mathrm{~Pa} \cdot \mathrm{s} \quad \operatorname{Pr}=6.22
\end{gathered}
$$

Thermal conductivity $(\lambda)$ is the quantity of heat transmitted through a unit thickness in a direction normal to a surface of unit area, due to a unit temperature gradient under steady-state conditions. Specific heat capacity $\left(c_{\mathrm{p}}\right)$ is defined as the heat required to raise unit mass of substance by one degree of temperature. Dynamic viscosity $(\eta)$ is the coefficient of internal friction of fluid. Prandtl Number $(\mathrm{Pr})$ is a dimensionless number approximating the ratio of momentum diffusivity and thermal diffusivity. Reynolds number $(R e)$ is a dimensionless number that gives a measure of the ratio of inertial forces to viscous forces and consequently quantifies the relative importance of these two types of forces for given flow conditions. Nusselt

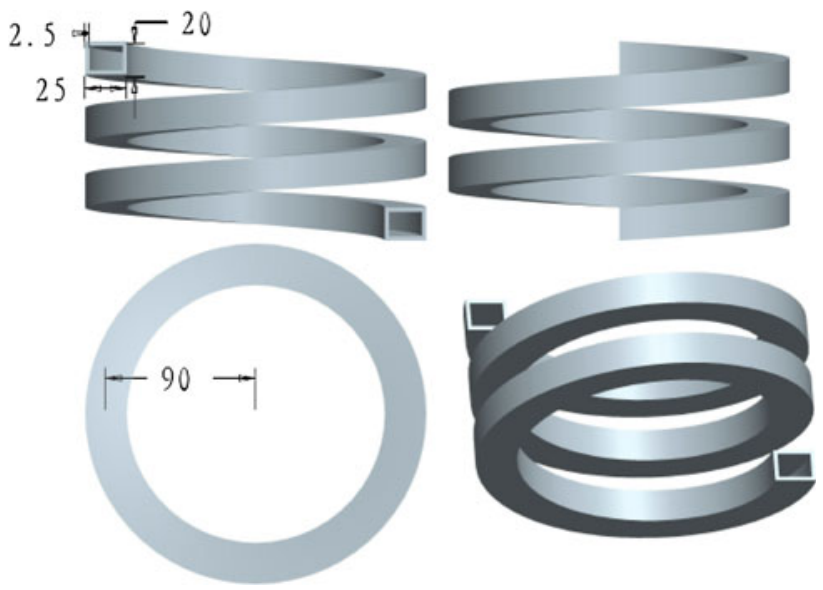

Fig. 2 Size of intermediate frequency induction coil

number $(\mathrm{Nu})$ is the ratio of convective to conductive heat transfer across the boundary. Heat transfer coefficient $(h)$, in thermodynamics and in mechanical and chemical engineering, is used in calculating the heat transfer, typically by convection or phase change between a fluid and a solid.

$\because$ coil is a square pipe

$\therefore$ equivalent diameter $d_{e}=\frac{4 A_{c}}{P}=22.22 \mathrm{~mm}$

$A_{\mathrm{c}}$ is the sectional area of coil, $P$ is the sectional perimeter of coil. 
$\because \operatorname{Re}=\frac{4 q_{m}}{\pi d_{e} \eta}=5.64 \times 10^{4}>10^{4}$

$\therefore$ This problem belongs to turbulent heat transfer.

$\because l / d_{e}=\frac{\pi D}{d_{e}}=25.449<60$

$\therefore$ It needs to introduce a correction factor $c_{l}$

$$
=1+\left(\frac{d_{e}}{l}\right)^{0.7}=1.1047
$$

$\because$ coil is helical

$\therefore$ It needs to introduce a correction factor $c_{r}$

$$
=1+10.3\left(\frac{d_{e}}{D / 2}\right)^{3}=1.155
$$

Do not consider compensating of difference in temperature, $c_{t}=1$

$$
\begin{aligned}
& N u=0.023 \operatorname{Re}^{0.8} \operatorname{Pr}^{0.4} c_{l} c_{r} c_{t}=385.317 \\
& h=N u \lambda / d_{e}=10560.668 \mathrm{~W} /\left(\mathrm{m}^{2} \cdot \mathrm{K}\right)
\end{aligned}
$$

Outlet temperature: $t_{2}=t_{w}-\left(t_{w}-t_{1}\right) \exp \left(-\frac{h P}{q_{m} c_{p}} l\right)$

$$
=24.78^{\circ} \mathrm{C}
$$

Heat release of coil: $\phi=n q_{m} c_{p}\left(t_{2}-t_{1}\right)$

$$
=4.438 \times 10^{5} \mathrm{~W}
$$

It can extract quantity of heat $\left(Q_{1}\right)$ from circulating water of hot-stamping induction coil per hour.

$Q_{1}=\phi \times t=1.598 \times 10^{6} \mathrm{KJ}$

When designing the circulation loop of medium frequency power supply required that circulating cooling water of converter and capacitor should take away 7.5 and $1.5 \%$ of total power. Namely, cooling system of power supply should take away $9 \%$ of total power (Li 2007).

It can extract quantity of heat $\left(Q_{2}\right)$ from circulating water of power supply per hour.

$$
\begin{aligned}
Q_{2} & =P_{1} \times t \times 9 \%=2000 \mathrm{~kW} \times 3600 \mathrm{~s} \times 9 \% \\
& =6.480 \times 10^{5} \mathrm{KJ}
\end{aligned}
$$

(2) trimming die of oil press and mould cooling

Through site investigation, the temperature of circulating water rises about $4{ }^{\circ} \mathrm{C}$ per hour of oil press and mould cooling.

It can extract quantity of heat $\left(Q_{3}\right)$ from circulating water per hour.

$$
\begin{aligned}
Q_{3} & =C \times m \times \Delta t \\
& =4179 \mathrm{~J} /\left(\mathrm{kg} \cdot{ }^{\circ} \mathrm{C}\right) \times 1 \times 10^{5} \mathrm{~kg} \times 4{ }^{\circ} \mathrm{C} \\
& =1.672 \times 10^{6} \mathrm{KJ}
\end{aligned}
$$

Closing-in technology

Similarly, outlet temperature $\left(t_{2}\right)$ of water and heat release $(\Phi)$ of coil can be calculated.

$t_{2}=t_{w}-\left(t_{w}-t_{1}\right) \exp \left(-\frac{h p}{q_{m} c_{p}} l\right)=24.60{ }^{\circ} \mathrm{C}$

$\phi=n q_{m} c_{p}\left(t_{2}-t_{1}\right)=2.136 \times 10^{5} \mathrm{~W}$

It can extract quantity of heat $\left(Q_{4}\right)$ from circulating water of closing-in induction coil per hour.

$Q_{4}=\phi \times t=7.689 \times 10^{5} \mathrm{KJ}$

According to the requirement that the cooling system of power supply should take away $9 \%$ of total power. It can extract quantity of heat $\left(Q_{5}\right)$ from circulating water of power supply per hour.

$$
\begin{aligned}
Q_{5} & =P_{2} \times t \times 9 \%=1000 \mathrm{~kW} \times 3600 \mathrm{~s} \times 9 \% \\
& =3.240 \times 10^{5} \mathrm{KJ}
\end{aligned}
$$

Warm extrusion technology

Similarly, outlet temperature $\left(t_{2}\right)$ of water and heat release $(\Phi)$ of coil can be calculated.

$t_{2}=t_{w}-\left(t_{w}-t_{1}\right) \exp \left(-\frac{h p}{q_{m} c_{p}} l\right)=25.63^{\circ} \mathrm{C}$

$\phi=n q_{m} c_{p}\left(t_{2}-t_{1}\right)=6.541 \times 10^{4} \mathrm{~W}$

It can extract quantity of heat $\left(Q_{6}\right)$ from circulating water of warm extrusion induction coil per hour.

$Q_{6}=\phi \times t=2.355 \times 10^{5} \mathrm{KJ}$

According to the requirement that the cooling system of power supply should take away $9 \%$ of total power. It can extract quantity of heat $\left(Q_{7}\right)$ from circulating water of power supply per hour.

$$
\begin{aligned}
Q_{7}= & P_{3} \times t \times 9 \%=500 \mathrm{~kW} \times 3600 \mathrm{~s} \times 9 \% \\
& =1.620 \times 10^{5} \mathrm{KJ}
\end{aligned}
$$

\section{Results analysis}

Due to circulating water in recycling process will inevitably have loss, therefore, in the production process water should be replenished in time. According to the site investigation compensating water should be 0.3 tons/ 
100 tons per hour. So compensating water volume should be $0.8 \mathrm{t} / \mathrm{h}$.

In the mixed process, temperature of compensating water will be increased from 20 to $25^{\circ} \mathrm{C}$. In this process, $Q_{8}$ heat will be taken away by compensating water per hour.

$$
\begin{aligned}
Q_{8} & =C \times m \times \Delta t=4.180 \times 800 \times 5 \\
& =1.672 \times 10^{4} \mathrm{KJ}
\end{aligned}
$$

m: compensating water flow, $0.8 \mathrm{t} / \mathrm{h}$ or $800 \mathrm{~kg} / \mathrm{h} . \Delta T$ : temperature difference, $5{ }^{\circ} \mathrm{C}$.

C: specific heat capacity of $23{ }^{\circ} \mathrm{C}$ water, $4.180 \mathrm{~kJ} /$ $\left(\mathrm{kg}{ }^{\circ} \mathrm{C}\right)$.

Through above calculation, $Q$ heat can be recovered from circulating cooling water of hot-stamping power system per hour.

$$
\begin{aligned}
Q & =Q_{1}+Q_{2}+Q_{3}+Q_{4}+Q_{5}+Q_{6}+Q_{7}-Q_{8} \\
& =5.392 \times 10^{6} \mathrm{KJ}
\end{aligned}
$$

According to the actual production need in heat pump units, the type of evaporator and condenser chose the shelland-tube heat exchanger. The efficiency of heat exchanger of shell-and-tube heat exchanger is commonly 0.6-0.8. In this calculation, the efficiency of evaporator $\left(\eta_{1}\right)$ and condenser $\left(\eta_{2}\right)$ are tentatively set at 0.7 (Guo 2009; Yang et al. 2009; Poddar and Polley 2000).

Heat pump can recover $Q_{9}$ of heat from circulating cooling water of hot-stamping power system per hour.

$Q_{9}=Q \times \eta_{1} \times \eta_{2}=2.642 \times 10^{6} \mathrm{KJ}$

Heat pump uses recyclable heat to heat water for production and life; it can provide $G$ tons of high temperature water which is $60{ }^{\circ} \mathrm{C}$ per hour.

$$
\begin{aligned}
Q_{9} & =C \times G \times \Delta t \\
G & =Q_{9} /(C \times \Delta t) \\
& =2.642 \times 10^{6} /[(4.174 \times(60-20)]=15.82 \mathrm{t}
\end{aligned}
$$

Coal consumption of boiler produces 15.82 tons water which is $60{ }^{\circ} \mathrm{C}$ is $G_{1}$.

$$
\begin{aligned}
& G_{1} \times q \times \eta_{3}=C \times G \times \Delta t=Q_{9} \\
& G_{1}=Q_{9} /\left(q \times \eta_{3}\right)=2.642 \times 10^{6} /(20934 \times 0.7) \\
& G_{1}=180.29 \mathrm{~kg}
\end{aligned}
$$

$G$ : water flow, $\Delta t$ : temperature difference. $\eta_{1}, \eta_{2}$ : efficiency of evaporator, efficiency of condenser, $C$ : specific heat capacity of $40{ }^{\circ} \mathrm{C}$ water, $4.174 \mathrm{~kJ} /\left(\mathrm{kg} \cdot{ }^{\circ} \mathrm{C}\right)$.

$q$ : calorific value of ordinary coal, $5,000 \mathrm{kcal}$ or $20,934 \mathrm{~kJ} / \mathrm{kg}$. $\eta_{3}$ : efficiency of industrial boiler, which is commonly 0.7 .
Table 2 Pollutant emissions load of industrial boiler when its combust 1 ton of standard coal

\begin{tabular}{llll}
\hline $\mathrm{CO}_{2}$ & $\mathrm{SO}_{2}$ & $\mathrm{~N}_{\mathrm{X}} \mathrm{O}$ & Dust \\
\hline $2,620 \mathrm{~kg}$ & $18.5 \mathrm{~kg}$ & $7.4 \mathrm{~kg}$ & $50 \mathrm{~kg}$ \\
\hline
\end{tabular}

Table 3 Decrement of pollutant emissions load in this project per year

\begin{tabular}{llll}
\hline $\mathrm{CO}_{2}$ & $\mathrm{SO}_{2}$ & $\mathrm{~N}_{\mathrm{X}} \mathrm{O}$ & Dust \\
\hline $2,418.5 \mathrm{t}$ & $17.1 \mathrm{t}$ & $6.8 \mathrm{t}$ & $46.2 \mathrm{t}$ \\
\hline
\end{tabular}

One day recover $16(\mathrm{~T})$ hours (two shifts, per shift work 8 h), work 320 days per year. So it can save standard coal, the quantity of which is about $G_{2}$.

$$
\begin{aligned}
G_{2} & =G_{1} \times T \times \mathrm{D} \\
& =180.29 \mathrm{~kg} / \mathrm{h} \times 16 \mathrm{~h} / \text { day } \times 320 \text { day } / \text { year } \\
& =923100 \mathrm{~kg} / \text { year }=923.1 \mathrm{t} / \text { year }
\end{aligned}
$$

It can save standard coal about 923.1t per year. According to the pollutant emissions load of the industrial boiler when its combust 1 ton of standard coal (as shown in Table 2), it can calculate that every year can reduce $\mathrm{CO}_{2}$ emissions load 2,418.5t, reduce $\mathrm{SO}_{2}$ emissions load 17.1t, reduce $\mathrm{N}_{\mathrm{X}} \mathrm{O}$ emissions load $6.8 \mathrm{t}$, reduce dust emissions load 46.2t (as shown in Table 3).

\section{Conclusions}

(1) The research made analysis about recoverable waste heat of circulating cooling water in hot-stamping power system. Research results lay a foundation for designing the waste-heat recovery system, and provide a basis for determining the waste-heat recovery technology.

(2) Through analysis of recoverable waste heat of circulating cooling water in the whole power system, it turned out that it can recover a calorie which is $2.642 \times 10^{6} \mathrm{~kJ}$ per hour. Using the recycled heat it can make 15.82 tons hot water per hour, which is $60{ }^{\circ} \mathrm{C}$. The procreative hot water can provide the needed water for production and workers bathing. So it can reduce burning capacity of coal $180.29 \mathrm{~kg} / \mathrm{h}$.

(3) Every year it can reduce $\mathrm{CO}_{2}$ emissions load 2,418.5t, reduce $\mathrm{SO}_{2}$ emissions load 17.1t, reduce $\mathrm{N}_{\mathrm{X}} \mathrm{O}$ emissions load 6.8t, reduce dust emissions load 46.2t.

Acknowledgments Natural science fund projects of Liao Ning Provice, China (20072007); Science and technology fund projects of Shen Yang, Liao Ning Provice, China (1063293) 
Open Access This article is distributed under the terms of the Creative Commons Attribution License which permits any use, distribution, and reproduction in any medium, provided the original author(s) and the source are credited.

\section{References}

Aziz A (2012) Convective-radiative fins with simultaneous variation of thermal conductivity, heat transfer coefficient, and surface emissivity with temperature. Heat Transf Asian Res 41(2):99-113

Chen YZ, Zhou YH, Ding XW (2002) Application of numerical heat transfer technology in heat transfer research of engineering heat exchange equipment. J Chem Ind Eng 23(3):21-25

Chen H, Qin PP, Chen LL, Yu LN, Liu SK (2011a) Analysis and determination of the thermal parameters in the waste heat recovery system based on heat pump. International conference on electric technology and civil engineering (ICETCE), Lushan, 22-24 Apr 2011, pp 1006-1008

Chen H, Chen LL, Qin PP, Yu LN, Liu SK (2011b) 58SiMn metallographic analysis and mechanical properties in the waste heat recovery system. Second international conference on mechanic automation and control engineering, 15-17 Jul 2011, Inner Mongolia, pp 1-3

Dogruoz M (2010) On the conduction and convection heat transfer from lightweight advanced heat sinks. IEEE Trans Compon Packag Technol 33(2):424-431

Guo J (2009) Optimization design of shell-and-tube heat exchanger by entropy generation minimization and genetic algorithm. Appl Therm Eng 29(14/15):2954-2960

Hui ZC (2011) Application and maintenance of the medium frequency furnace. Foundry Technol 4:583-585

Jeong HM (2009) Natural convection heat transfer estimation from a longitudinally finned vertical pipe using CFD. J Mech Sci Technol 23(6):1517-1527
Lei W, Bengt S (2006) Experimental investigation of local heat transfer in a square duct with various-shaped ribs. Heat Mass Transf 43(8):759-766

Li YH (2007) Induction heating in forge and stamp industry: water cooling system of induction heating equipment. Machinist Metal Form 11:79-82

Li N, Zhang JC (2010) Analysis of energy saving for hydraulic system of large hydraulic press. Mach Tool Hydraul 38(12):75-76

Li J, Zhou Y (2007) Recovery and application of steam condensation water. Energy China 9:42-43

Lian HK, Li Y, Shu GYZ, Gu CH (2011) An overview of domestic technologies for waste heat utilization. Energy Conserv Technol 29(2):123-128, 133

Lu YH (2011) Research of intermediate frequency induction furnace. Mod Bus Trade Ind 19:367-368

Ma HB (2008) Heat transport capability in an oscillating heat pipe. J Heat Transf 130(8):081501

Poddar TK, Polley GT (2000) Optimize shell-and-tube heat exchanger design. Chem Eng Prog 96(9):41-46

Spoelstra S, Haije WG, Dijkstra JW (2002) Techno-economic feasibility of high-temperature high-lift chemical heat pumps for upgrading industrial. Appl Therm Eng 22:1619-1630

Verzicco R (2004) Effects of nonperfect thermal sources in turbulent thermal convection. Phys Fluids 16(6):1965-1979

Wang NN (2001) Criterion of convection heat transfer in heat transfer theory. J Jiangxi Electr Power Univ Staff 14(2):47-48

Wang QB, Wang HB, Hu JK (2005) Research on several problems in hydraulic system design of hydraulic press. Mach Tool Hydraul 5:78-79, 81

Yang M, Meng XF, Zhang WJ (2009) Optimal design of shell-and-tube heat exchanger. J Beijing Univ Aeronaut Astronaut 5:615-617, 648

Zhou Y, Wang K, Chen SM (2002) Technology outlook and condition of waste heat utilization. Sci-Tech Inf Dev Econ 22:1619-1630 